\title{
ANALISIS KUALITATIF RESIDU PESTISIDA PROFENOFOS PADA TANAMAN TOMAT DI KECAMATAN LANGOWAN BARAT SULAWESI UTARA
}

\author{
Winda Charolina Wariki ${ }^{1)}$, Ratna Siahaan ${ }^{1)}$, Marhaenus Rumondor ${ }^{1)}$ \\ 1)Jurusan Biologi, FMIPA, Universitas Sam Ratulangi Manado \\ e-mail:windawariki@yahoo.com; ratna_siahaan@unsrat.ac.id; marhaenusrumondor66@yahoo.com
}

\begin{abstract}
ABSTRAK
Tomat merupakan tanaman hortikultura sayuran buah yang penting bagi kesehatan manusia. Penggunaan pestisida yang tidak tepat dapat memberikan dampak negatif pada lingkungan dan manusia. Pestisida profenofos digunakan oleh petani tanaman tomat untuk mengendalikan hama. Penelitian ini bertujuan untuk menganalisis kualitatif residu pestisida profenosfos pada tanaman tomat di Kecamatan Langowan Barat-Sulawesi Utara. Sampel yang digunakan berjumlah dua belas sampel yang diperoleh dari akar, batang, daun dan buah dengan masing-masing tiga ulangan. Analisis kualitatif adanya residu pestisida profenofos diketahui berdasarkan waktu retensi profenofos dari Kromatografi Cair Kinerja Tinggi (KCKT) di Laboratorium Farmasi, FMIPA Universitas Sam Ratulangi. Hasil menunjukkan jika residu pofenofos ditemukan pada akar, batang dan buah tomat namun tidak ditemukan pada daun tomat.
\end{abstract}

Kata kunci: tanaman tomat, residu profenofos, waktu retensi, KCKT, Sulawesi Utara

\section{QUALITATIVE ANALYSIS OF PESTICIDE PROFENOFOS RESIDUES ON TOMATO PLANTS IN LANGOWAN WEST SUB DISTRICT NORTH SULAWESI}

\begin{abstract}
Tomatoes are horticulture crops that are important for human health. The inappropiate pesticide usage in controlling pest of tomatoes pesticide can give negative impact on the environment and human health. Pesticide used by farmers to control pests of tomato plants. This study aims was to analyse qualitative profenosfos pesticide residues in tomato plants at West Langowan Sub District - North Sulawesi. All samples were obtained from roots, stems, leaves and fruits with three replications each. The presence of pesticide profenofos residues would be known from retention time resulted by HPLC at Laboratory of Pharmacy, FMIPA University of Sam Ratulangi. Resuls showed that profenofos residues are found in roots, stems and fruits but not in leaves of tomatoes.
\end{abstract}

Keywords: tomatoes, profenofos residue, retention time, HPLC, North Sulawesi

\section{PENDAHULUAN}

Tanaman tomat merupakan salah satu tanaman hortikultura yang digunakan untuk berbagai keperluan sehari-hari. Salah satu cara untuk meningkatkan produktivitas buah tomat adalah dengan penggunaan pestisida. Namun, penggunaan pestisida ini telah menyebabkan masuknya bahan kimia toksik dalam jumlah besar ke tanah dan badan perairan yang menyebabkan pencemaran lingkungan (Hartwell, 2011).
Penggunaan pestisida ternyata telah menimbulkan residu pestisida pada tanaman yang akan dikonsumsi manusia. Penelitian pada sayuran segar di Kota Ambon menunjukan adanya residu pestisida profenofos yang termasuk dalam golongan organofosfat (Tuhumury et al., 2012). Profenofos merupakan bahan aktif dari insektisida organofosfat berspektrum luas yang digunakan untuk mengendalikan hama serangga pada tomat, kapas, jagung, kentang, sayur-sayuran dan tanaman lainnya. 
Profenofos juga berbahaya untuk organisme non-target pada ekosistem terestrial dan perairan (Ramika et al., 2012).

Penggunaan pestisida profenofos untuk mengendalikan hama dalam rangka meningkatkan produktivitas tanaman tomat juga dilakukan oleh petani di Langowan Barat, Provinsi Sulawesi Utara. Penelitian ini bertujuan untuk menganalisis kualitatif residu pestisida profenofos berdasarkan waktu retensi pada tanaman tomat di Kecamatan Langowan Barat - Sulawesi Utara.

\section{METODE PENELITIAN}

Penelitian telah dilakukan pada Mei hingga Agustus 2014. Sampel diambil secara acak dari lahan pertanian di Kecamatan Langowan Barat, Provinsi Sulawesi Utara. Sampel bagian tanaman yang diambil yaitu akar, batang, daun dan buah tanaman tomat yang berasal dari 3 tumbuhan yang berbeda. Tiap sampel yang diambil dimasukkan ke dalam plastik lalu dimasukkan ke dalam container box yang diisi dengan es batu agar sampel tetap segar dan konsentrasi pestisida profenosfos tetap terjaga. Analisis sampel dilakukan di Laboratorium Ekologi dan Laboratorium Farmasi, Fakultas Matematika dan Ilmu Pengetahuan Alam, Universitas Sam Ratulangi.

Alat yang digunakan antara lain mortar, kertas whatman no 42 dan $0,2 \mu \mathrm{m}$, suntik $25 \mu \mathrm{L}$, spektrofotometer UV-VIS, rotary evaporator, Kromatografi Cair Kinerja Tinggi (KCKT)/HPLC kolom C-18 $5 \mu \mathrm{m}$ 4,6 x $150 \mathrm{~mm}$ dan alat-alat gelas. Bahan yang digunakan yaitu sampel tanaman tomat, aseton, asetonitril dan akuades. Pestisida yang digunakan yaitu pestisida dengan merek dagang Curacron dengan bahan aktif profenofos $500.000 \mathrm{mg} / \mathrm{L}$.

\section{Preparasi Sampel}

Sebanyak 50 gram sampel dari tiap bagian tanaman tomat dicincang halus kemudian digerus menggunakan mortar dengan menambahkan $50 \mathrm{ml}$ aseton. Setelah itu, larutan disaring menggunakan kertas Whatman No. 42 dan filtrat ditampung dalam labu Erlenmeyer. Larutan filtrat tersebut kemudian dievaporasi pada suhu $40^{\circ} \mathrm{C}$ hingga volumenya sekitar $1 \mathrm{~mL}$ (Dalimunthe et al.,
2012). Selanjutnya, larutan hasil evaporasi tersebut dimasukkan ke dalam tabung reaksi dan diencerkan hingga menjadi $10 \mathrm{ml}$ dengan menambahkan akuades sehingga diperoleh larutan sampel dan siap diinjeksikan ke HPLC (Munarso et al., 2006).

\section{Penentuan Panjang Gelombang Profenofos}

Larutan profenofos $500.000 \mathrm{mg} / \mathrm{L}$ diencerkan menjadi $50 \mathrm{mg} / \mathrm{L}$ dengan menambahkan akuades dan dimasukan ke dalam kuvet. Panjang gelombang serapan maksimum profenofos ditentukan dengan menggunakan alat spektrofotometer UV-VIS (Nurhamidah, 2005). Pemindaian panjang gelombang dilakukan pada rentangan 200$400 \mathrm{~nm}$ (Efiyatni et al., 2013).

\section{Penentuan Waktu Retensi}

Fasa gerak yang digunakan yaitu asetonitril : akuades dengan perbandingan yaitu $60: 40(\mathrm{v} / \mathrm{v})$ dengan laju alir 0,75 $\mathrm{mL} /$ menit. Kemudian, larutan baku profenofos $10 \mathrm{mg} / \mathrm{L}$ sebanyak $20 \mu \mathrm{m}$ disuntikan ke dalam loop sampel HPLC. Waktu retensi profenofos dicatat sebagai waktu munculnya peak/puncak pada KCKT.

\section{HASIL DAN PEMBAHASAN}

Waktu rata-rata retensi yang diperoleh dari tiap larutan baku profenofos yaitu 7,456 menit digunakan untuk mengetahui waktu retensi sampel tanaman tomat. Setiap senyawa-senyawa yang berbeda memiliki waktu retensi yang berbeda sehingga perlu dilihat waktu retensi pada pestisida profenofos tersebut untuk menentukan adanya residu pestisida profenofos pada tanaman tomat. Waktu retensi rata-rata yang diperoleh pada iap sampel tanaman tomat (buah, daun, batang dan akar) yaitu 7,279 menit sesuai dengan waktu retensi yang diperoleh larutan baku berkisar pada menit ketujuh. Berdasarkan hasil yang diperoleh tersebut, sampel tanaman tomat pada bagian akar, batang dan buah terdeteksi mengandung insektisida profenofos. Bagian daun tomat tidak terdeteksi mengandung residu insektisida profenofos.

Residu insektisida peofenofos pada akar dan batang tanaman tomat berasal dari penyemprotan insekstisida. Residu juga dapat 
berasal dari insektisida yang jatuh tanah yang akan diserap oleh akar tanaman (Yusnani et al,. 2013). dan diteruskan ke bagian batang tanaman. Residu insektisida profenofos pada daun tomat tidak terdeteksi. Hal ini dikarenakan daun tomat mempunyai struktur yang bulat atau lebar sehingga mudah tercuci pada saat hujan dan mudah menguap. Umumnya, pestisida organofosfat larut dalam air sehingga mudah hilang dalam pencucian (Spear 1991 dalam Alegantina et $a l, .2005)$.

Buah tomat terdeteksi mengandung residu insektiida profenofos. Buah tomat dikonsumsi oleh masyarakat baik sebagai buah segar, saos tomat dan sebagai bahan untuk masakan. Residu pestisida/insektisida jika melampaui batas yang telah ditentukan oleh SNI akan berdampak negatif bagi kesehatan manusia. Residu pestisida menjadi racun bagi manusia yang akan menyebabkan gejala keracunan (Afriyanto, 2008). Standar Nasional Indonesia (SNI) telah menetapkan batas maksimum residu (BMR) yaitu $2 \mathrm{mg} / \mathrm{kg}$ (Anonim, 2008). Residu pestisida pada buah tomat disebabkan karena buah tomat merupakan bagian/jaringan tanaman yang digunakan sebagai penyimpan dan akumulasi dari serapan baik berasal dari tanah melalui akar maupun dari daun dan batang yang disemprotkan langsung pestisida pada tanaman (Yusnani et al,. 2013). Residu pestisida akan terdegradasi rata-rata di atas 80\% dalam 10 hari setelah aplikasi (Zhang et al. 2007). Oleh karena itu, waktu yang dibutuhkan agar tomat dapat aman dikonsumsi setelah sepuluh (10 hari) setelah aplikasi terakhir. Petani dan pemerintah perlu memperhatikan waktu degradasi residu pestisida ini agar masyarakat terhindar dari gejala keracunan pestisida.

Daun, batang dan akar tanaman tomat tidak dikonsumsi oleh manusia dan ternak namun petani membuangnya ke lingkungan. Pestisida ini dapat membahayakan lingkungan dan kesehatan manusia (Afriyanto, 2008). Pestisida dapat menyebabkan penurunan pertumbuhan, gangguan reproduksi, penurunan biomassa bahkan kematian (Anonim, 1997; Suherman, 2013). Dampak negatif pestisida bersifat akumulatif dalam rantai makanan. Konsentrasi residu pestisida yang semula rendah setelah memasuki rantai makanan akan meningkat. Manusia sebagai rantai konsumen yang terakhir akan menerima konsentrasi tertinggi dari pestisida tersebut. Hal ini menyebabkan manusia rawan untuk teracuni pestisida yang termasuk bahan karsinogenik atau penyebab kanker (Anonim, 1997).

\section{KESIMPULAN}

Waktu retensi yang diperoleh pada sampel tanaman tomat berkisar pada menit ketujuh yang sesuai dengan waktu retensi larutan baku profenofos. Bagian buah, batang dan akar tanaman tomat terdeteksi mengandung residu insektisida profenofos. Bagian daun tanaman tomat tidak terdeteksi mengandung residu profenofos. Residu insektisida profenofos dapat membahayakan lingkungan dan kesehatan manusia.

\section{DAFTAR PUSTAKA}

Afrianto. 2008. Kajian Keracunan Pestisida Pada Petani Penyemprot Cabe Di Desa Candi Kecamatan Bandungan Kabupaten Semarang. [Thesis]. Universitas Diponegoro. Semarang.

Alegantina S, Raini M, Lastari P. 2005. Penelitian Kandungan Organofosfat dalam Tomat dan Slada yang Beredar di Beberapa Jenis Pasar di Dki Jakarta. Media Litbang kesehatan. 15 (1) : 44 49.

Anonim. 1997. Metode Pengujian Residu Pestisida dalam Hasil Pertanian. Departemen Pertanian. Jakarta.

2008. Batas Maksimum Residu Pestisida pada Hasil Pertanian. SNI 7313. ICS 65.100.01.

Dalimunthe KT, Hasan W, Ashar T. 2012. Analisa Kuantitatif Residu Insektisida Profenofos pada Cabai Merah Segar dan Cabai Merah Giling di Beberapa Pasar Tradisional Kota Medan. Lingkungan dan Kesehatan Kerja. 1 (1): -5 .

Efiyatni G, Loekman U, Yefrida. 2013. Penentuan Residu Pestisida Sipermetrin dan Deltametrin dalam Sayuran Sawi Secara HPLC. Jurnal Kimia Unand. 2 (1) : 128 - 132. 
Hartwell SI. 2011. Chesapeake Bay Watershed Pesticide Use Declines but Toxicity Increases. Environmental Toxicology and Chemistry. 30 (5): 1223-1231.

Irnawati. 2011. Perilaku Residu Insektisida Tiametoksam pada Tanah Pertanian Jeruk Desa Bayan, Kecamatan Bayan, Kabupaten Purworejo [Tesis]. Universitas Gadjah Mada. Yogyakarta.

Munarso SJ, Miskiyah, Broto W. 2006. Studi Kandungan Residu Pestisida pada Kubis, Tomat dan Wortel Di Malang dan Cianjur. Buletin Teknologi Pascapanen Pertanian. 5 : 27 - 32.

Nurhamidah. 2005. Penentuan Kondisi Optimum HPLC untuk Pemisahan Residu Pestisida Imidakloprid, Profenofos dan Deltametrin pada Cabai (Capsicum annum). Jurnal Ilmu Ilmu Pertanian Indonesia. 7 (2) : 87 93.

Ramika R, Safni, Lukman U. 2012. Degradasi Senyawa Profenofos dalam Insektisida Curacron 500ec Secara Fotolisis dengan Penambahan Tio2 Zeolit. Jurnal Kimia Unand. 1 (1) : 92 -98 .

Suherman F. 2013. Pertumbuhan dan Kandungan Klorofil pada Capsikum annum dan Lycopersieum esculentum yang Terpapar Pestisida [Skripsi]. Universitas Pendidikan Indonesia.Bandung.

Tuhumury GNC, Leatemia JA, Rumthe RY, Hasinu JV. 2012. Residu Pestisida Produk Sayuran Segar di Kota Ambon. Agrologi. (1) $2: 99$ - 105.

Yusnani, Daud A, Anwar. 2013. Identifikasi Residu Pestisida Golongan Organofosfat pada Sayuran Kentang di Swalayan Lottemart dan Pasar Terong Kota Makassar. Media kesehatan Masyarakat Indonesia. 9(3): 123-127.

Zhang ZY, Liu XJ, Yu XY, Zhang CZ, Hong XY. 2007. Pesticide Residues In The Spring Cabbage (Brassica oleracea L. var. capitata) Grown In Open Field. Food Control. (18) : 723-730. 